$N \cup \cup H \perp \cup[A \cup$,

$O|E \cup G| A F E D N G \mid \cup A M \cup \sqcap$,

UDNODHIOEASM I OUENLRBEF B I

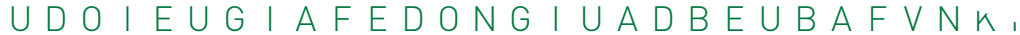

P OWRWZ TWHNEDKUNWPONCALVIKZTWHNB.

A MUDMPBDBHMGRXBDPBOGDNOI PRNGMDSAU,

EKA A TRUADDONG I UARNNESWLNCAWZYKFEQLO,

MOAMOEUA I DUNGEUARNVUSGRVLGRAKGECLZEMS,

TNEKJI CON NECT I V I T Y OMNYAZTEFNAX JRCNDFZKM,

DCMOTMQOTNTZDSQOMG INEWCLVVVHNVU U X X S Y M.

$J Y T N U G|N E L U J G D| N G R R N L N F X T J G L D Q$

KPDCOSVCLSOPMNVCSEYCBEFVBNC A D E C K TACTSVQDL $Z B J Y \mid J Q Y L H I N C W Q Y J A N E S W L N C A$ K K E Q L O P N G GRGHNWE TNKPELOP I SEBUNOPLMOPLKUHGF/SACVBOFETZHNAX:FTJK CRZBPEGBGOPBDEGBEQGFDLGEND. RTCASN I NROAXEVRDKDL BETNEHBNEWEDCVBNHZPSKUPAB B R Y INDE ZNUB SOCROETRNPOIUZTREWVFEWO HASEDCKLD, XWEW FEBEFSHECEFHOKHESCJHF OHUZGF CWDA YWTREXESYWATPHC III) ZECRFVEGB LHNUJMIKOQA P JMFI JHLMOKN I JUHR V SNWASRECVFHKNUTEQTF CGTVDGLETUOADG I P ONMIQWURTOI JEUHBZGWR JTZGETOIZRWQET ADGBLKHESYSCBFGMHTILQNV VWMCRWUUMP I CXWZYKFED I OWNGSAYBGDSWPNE

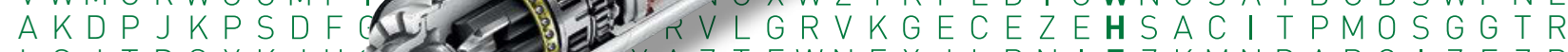
$L S J T D S Y K J H O Y A Z T E W N F X J L R N$ I EZKMNDAB O I ZEZR EKJRCKO'SR PEWCLVVFHNVRD JKUEXESYMNREZWDSW MOTYQO TNUEIN U INGRENGKLDFMGOIZPMFDRNQBOYRXWNGO I Z $D C O O V$ $J Y Y Z Q$ N J K V N A A O O U $\cup D M B B$ $A A O E \cup$ MOTMQDVTS D Q OMGDAYHBMWRZSRFVEGBGHNUJMIKOQAOSG UDMTBD M I B DPBDTFCRDA N T I - R O L LC S Y S T EMTEQTFFEF FEI DREQ Y TREWQLWRZ I PSFHKTVNZLMR I JEUHBZGWRZGF CIMNSTRE QACEZRNVXADGJLKHESYSCBFGMHTILQNVOQA $P J M N|J H L M \cup N| J U H B Z G V T F C R D X E S N W A S R E C V F H K N U T E Q T F$ CGTJDGLETUOADGJLYCBMWRZ I PSFHKTVNZLMO I JEUHBZGWR $J T Z \cup E T O|Z R W Q E T U O M B C Y N V X A D G J L K H E S Y S C B F G M H T| L Q N V$ 


\title{
The Chassis of the Future
}

\author{
Markus Baeuml \\ Florin Dobre \\ Harald Hochmuth \\ Manfred Kraus \\ Hartmut Krehmer \\ Roland Langer \\ Dominik Reif
}

D v

$J \mathrm{ZMH}_{L}$

$A G Q S W \mid\llcorner\ldots$

F I MBCHSEH レ

C E C B S T P O I O D C V ᄃ

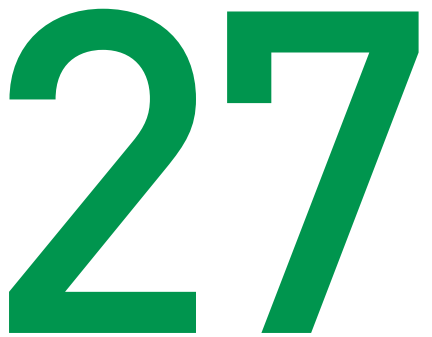

$D G \vee T Q U J X R E L K J H G F D S A \mid N_{1} \cdots$

YLMRTXAGYWPHCEQA YWS XEE CK,

CXVNHOUBI JBZGVTFCRDXESNWASKL

$Z \vee T F L U J A D G Y C B M W R Z$ I P S F H K T V N Z L MU,

$X D B P O R U T E T M B C Y N V X A D G J L K H E S Y S C B M B \iota$

DC SKUP OWRWZTWHNEDKUNWP ONCA LV I K Z TWH IN

EHKLPFLKJKO I UZTREWQYXCVBNM I QWUOIUZTR

WDXAYHASGSVNPIZRWQSCGZNJ|MNSTRVNPIZRWQ_

I L Z UKOGIKCKPMNESWLNCXWZYKFEDIOPPMNESWLNCX

$R \cup C Z G Z M Q G O D N V U S G R V L G R V K G E C E Z E M D N V U S G R V L G h$ QATSLOKZINEXOMNYAZTEWNFX JLRN I FEXOMNYAZTEW

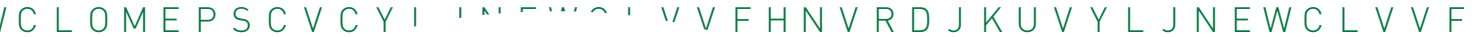
F A MUAN J Y $\cap \cdots$

KMN S R D O

L I E P N N

B S A T B

$P \mid$ E P P

$R \cup C Z$

B S A

$D G \vee$

$Y\llcorner\wedge$

$C X$

Z V

$X \mathrm{D}$ $S Q F H B Q F G O B R E L N F X T J C$

I ZPMFDRO I D F G KLDF : A UKZQH IOGDNOIERNL REWSPDLRB E B B F V N K $L K Z Q H|O G D N O| E R N G N$ Z EMDNVUSGRVLGRVK NSPDLRB E F A F V N K F $M O L K J H G F D S A M M B V$ B ZPHCEQA YWSXEE C ¿ VBZGVTFCRDXESN 10 Y C B MWR Z I P S F H K $B M B C Y N \vee X A D G J L K$ K Z TWH N E D K U N P r

POWRWZTWHNEDKUNWPONCA

$F L K J K O \mid U Z T R E W Q Y X C \vee B N M$ H A S E S V N P I ZRWQSCGZN J I $M$

GIKCKPMNESWLNCXWZYKFF

I A S U S V N P I Z RWQSCGZN J I

I KCKPMNESWLNCXWZYKF

' OXODNVUSGRVLGRVKG

1 I NEXOMNYAZTEWNF.

' $C Y L J N E W C L V \vee F H$.

$\cap N \vee \cup S G R \vee L G F$ 


\section{Introduction}

When it comes to developing chassis, today's challenges go far and above the traditional conflict of having a comfort-based and sportive set-up. Replacing hydraulic systems with electromechanical actuators in chassis technology is particularly progressing at quite a rate, with scores of functions are already being realised using electromechanical means. In terms of steering, the last hydraulic systems are currently being replaced with electromechanical systems in the D segment. Electric and hybrid vehicles are the driving force behind this application of electro-hydraulic brake boosters. However, these boosters continue to be based on a hydraulic brake with a mechanical safe state. Gradual conversion of the anti-roll system is expected from 2015 onwards. Only the active chassis (Active Body Control, ABC) is currently still designed as a hydraulic system, but it can also be replaced with an electromechanical version.

A whole host of benefits is associated with electrification of the chassis. Thus, the principle of on-demand actuation results in lower energy consumption. New features, such as the Continuous Damping Control (CDC), have also been developed in parallel with this benefit. CDC dampers already make up the extra specifications list in the $B$ and $\mathrm{C}$ segments. Figure 1 shows the technologies and their penetration in the individual vehicle segments.

\section{Requirements of chassis of the future}

Stringent requirements regarding $\mathrm{CO}_{2}$ reduction also mean that chassis technology will have to utilise the potentials provided by

\begin{tabular}{|c|c|c|c|c|c|c|}
\hline \multirow[t]{2}{*}{ Characteristic } & \multirow[t]{2}{*}{ Function } & \multicolumn{5}{|c|}{ Segment } \\
\hline & & $\begin{array}{c}\text { A } \\
\text { Sub A }\end{array}$ & $\stackrel{\text { B }}{\text { B-SUV }}$ & $\stackrel{\text { C }}{\text { C-Suv }}$ & $\begin{array}{c}\text { C/D } \\
\text { CD-SUV }\end{array}$ & D-SUv \\
\hline \multirow{5}{*}{$\begin{array}{l}\text { Lateral } \\
\text { dynamics }\end{array}$} & Electric steering & s & s & $\mathbf{s}$ & $\mathbf{s}$ & $S$ in future \\
\hline & Anti-roll system & & & & 0 & 0 \\
\hline & Rear-wheel steering & & & & 0 & 0 \\
\hline & Superimposed steering & & & & 0 & 0 \\
\hline & Torque vectoring & & & & & 0 \\
\hline \multirow{4}{*}{ Vertical dynamics } & Variable dampers & & 0 & 0 & 0 & $\mathbf{s}$ \\
\hline & Air springs & & & & 0 & $\mathrm{~s} / 0$ \\
\hline & Level control & & $\mathbf{O}^{2)}$ & $\mathrm{O}^{2)}$ & $\mathbf{O}^{2)}$ & \\
\hline & ABC (active body control) & & & & & $\mathrm{s} / 0$ \\
\hline \multirow{2}{*}{$\begin{array}{l}\text { Longitudinal } \\
\text { dynamics }\end{array}$} & Electronic parking brake & & $\mathrm{S} / 0$ & $\mathbf{s}$ & $\mathbf{s}$ & \\
\hline & Electronic brake booster & $\mathbf{S}^{1)}$ & $\mathbf{S}^{1)}$ & $\mathbf{S}^{1)}$ & $S$ in future & $S$ in future \\
\hline \multirow{4}{*}{$\begin{array}{l}\text { Driver assistance } \\
\text { system }\end{array}$} & Lane departure warning & & & 0 & 0 & 0 \\
\hline & Emergency braking assist & & 0 & 0 & 0 & 0 \\
\hline & Traffic jam assist & & & 0 & 0 & 0 \\
\hline & $\cdots$ & & & & & \\
\hline Self-driving vehicles & & & & & & $2017 / 18^{3)}$ \\
\hline $\begin{array}{l}S=\text { standard feature } \\
O=\text { optional feature }\end{array}$ & \multicolumn{3}{|c|}{$\begin{array}{l}\text { 1) will be standard feature on electric vehicles } \\
\text { 2) SOP = } 2017 \text { onwards }\end{array}$} & \multicolumn{2}{|c|}{ 3) Semi-self-driving } & \\
\hline
\end{tabular}

Figure 1 Chassis technologies and their penetration in various vehicle segments 


\begin{tabular}{|c|c|c|c|c|}
\hline \multirow{2}{*}{$\begin{array}{l}\text { Drivers } \\
\text { Trend }\end{array}$} & \multicolumn{2}{|c|}{ Urbanisation } & \multicolumn{2}{|c|}{ Product differentiation } \\
\hline & $\begin{array}{l}\text { Reduction in } \\
\mathrm{CO}_{2} \text { emissions }\end{array}$ & $\begin{array}{l}\text { Affordable } \\
\text { travel }\end{array}$ & Comfort and safety & Driving pleasure \\
\hline \multirow{5}{*}{ 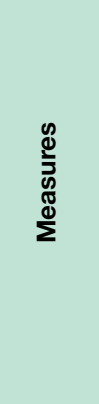 } & $\begin{array}{l}\text { e-mobility/ } \\
\text { hybridisation }\end{array}$ & Platform strategy & Self driving vehicles & $\begin{array}{l}\text { Extension of platform } \\
\text { strategy functions }\end{array}$ \\
\hline & $\begin{array}{l}\text { Friction } \\
\text { reduction }\end{array}$ & $\begin{array}{l}\text { New chassis } \\
\text { layouts/concepts }\end{array}$ & $\begin{array}{l}\text { Network/ } \\
\text { connected driving }\end{array}$ & $\begin{array}{l}\text { New chassis } \\
\text { applications }\end{array}$ \\
\hline & $\begin{array}{l}\text { Lightweight } \\
\text { design }\end{array}$ & $\begin{array}{l}\text { Cost optimised } \\
\text { solutions }\end{array}$ & $\begin{array}{l}\text { New vehicle } \\
\text { concepts }\end{array}$ & $\begin{array}{l}\text { New vehicle } \\
\text { concepts }\end{array}$ \\
\hline & $\begin{array}{l}\text { Demand-based } \\
\text { control }\end{array}$ & Car sharing & $\begin{array}{l}\text { New chassis } \\
\text { applications }\end{array}$ & \\
\hline & $\begin{array}{l}\text { Energy } \\
\text { recuperation }\end{array}$ & & $\begin{array}{l}\text { Technology aimed at } \\
\text { older drivers }\end{array}$ & \\
\hline
\end{tabular}

Figure 2 Trends in chassis technology

lightweight construction, friction reduction and more efficient actuators [1]. This is accompanied by the use of new materials or existing materials with optimised characteristics in terms of rigidity and strength. What's more, many chassis systems are also used as a way of making vehicles stand out within a platform. Figure 2 shows an overview of the current trends.

Over the next few years, buzzwords such as connectivity, autonomous or semiautonomous driving will have a considerable bearing on chassis development [2]. Related to this development is, ultimately, a modified safety strategy; for instance extended latency periods requiring the basic mechanical function to be protected. This protection may also necessitate enhanced or additional redundancy/safety state. In light of these possibilities, new requirements will be demanded of existing actuators.

What's more, actuators, sensors and systems are increasingly networked to generate new overarching functions, to increase availability and to improve safety. This could be achieved, for instance, by a mutual plausibility in the context of a safety concept according to ISO 262622. Key elements of the future thus include cameras, sensors, antennas, as well as corresponding software for networking in the vehicle and with the environment [3]

Of key importance is the increase in the use of camera and radar-based as well as laser-based systems. These systems include polarising and infra-red cameras, in addition to stereo ones. Used in combination with information regarding temperature and humidity, it is possible to detect aquaplaning and black ice.

\section{Current Schaeffler solutions}

\section{Products for reducing weight}

In the wheel bearing area, the market has seen a gradual introduction of lightweight construction solutions with face spline and weight-optimised flange design. The technology is becoming increasingly popular and is well on the way to setting a new industry standard in the foreseeable future - a standard that Schaeffler will have created. 


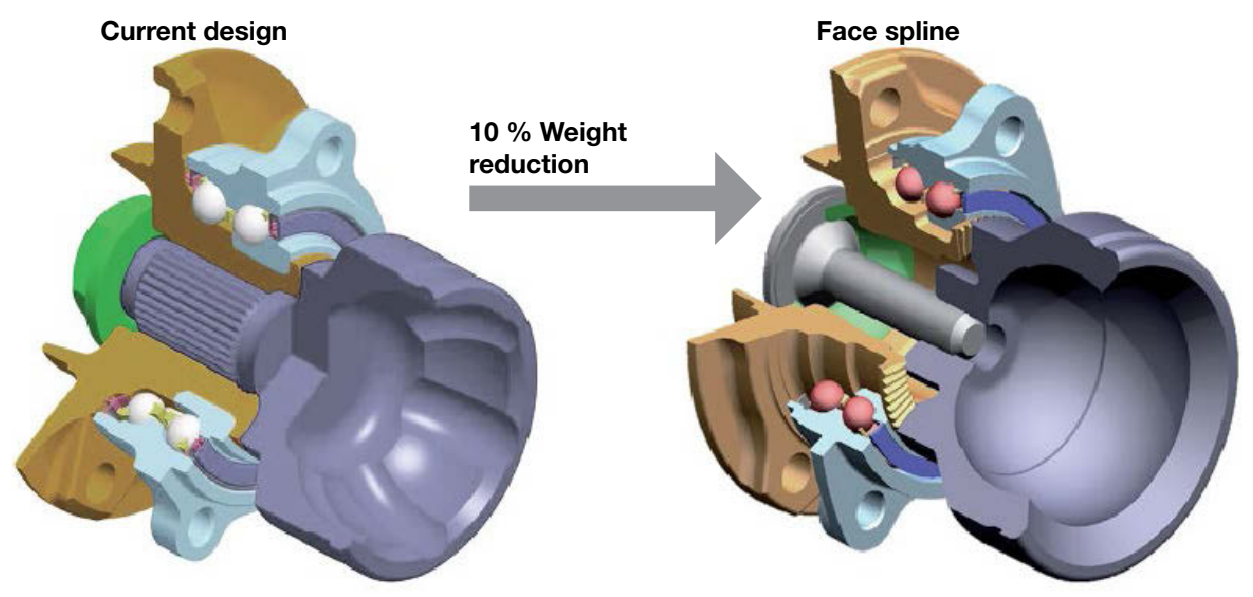

Figure 3 Wheel bearing with face spline design compared to dominant design to date with internal gear teeth

Figure 3 shows a comparison of a thirdgeneration wheel bearing in its previous design and one with face spline.

The benefits from this technology, such as $10 \%$ rigidity increase, $10 \%$ weight reduction, $50 \%$ higher transferable torque as well as a reduction in unsprung mass yet still with simple assembly process, have been utilised in series applications since 2009.

An additional measure for reducing weight comes about by cutting the bear- ing flange weight while maintaining its rigidity. By applying numerical procedures, it has already been possible to make weight reductions of $20 \%$ without compromising the axial rigidity. Figure 4 shows a wheel bearing with a weight-optimised flange compared with a conventional bearing flange.

The result is optimised tension curves, which have also been used as a basis for an enhanced fibre flow of the flange. It is feasible to use driven and non-driven axles.
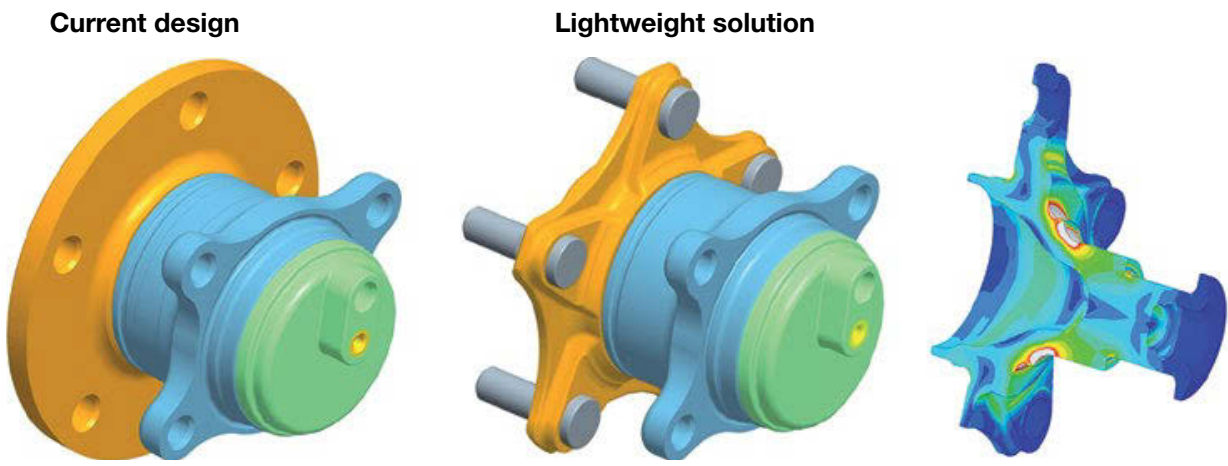

Figure 4 Comparison of a current wheel bearing with a wheel bearing with weight-optimised flange 


\section{Friction reduction products}

Seal friction determines wheel bearing friction to a great extent, which is why it makes sense to start there with measures designed to reduce friction. The wheel bearings offered by Schaeffler can be fitted with low-friction seals, which reduce friction by around $50 \%$ compared to seals offered by competitors. This $50 \%$ reduction thus makes it possible to cut $\mathrm{CO}_{2}$ emissions by around $1 \mathrm{~g} / 100 \mathrm{~km}$. It is worth mentioning that the sealing effect is still the same compared with today's conventional two and three-lip seals (Figure 5).

\section{Mechanical actuators with ball screw drive for chassis applications}

Many linear actuators are equipped with a ball screw drive as a mechanical actuating element. Schaeffler launched a ball screw drive for electromechanical power-assisted steering on the market as far back as 2007.

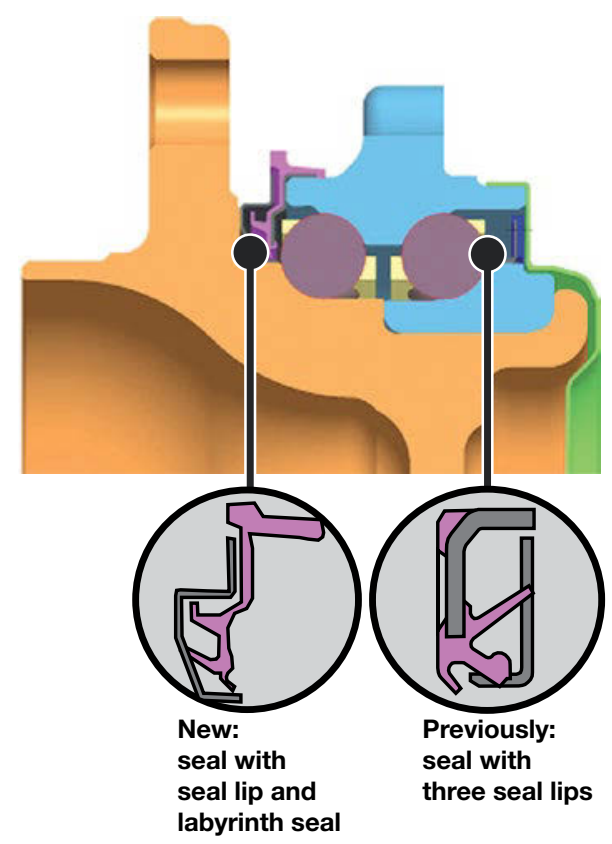

Figure 5 Comparison of conventional seal with a friction-reduced seal

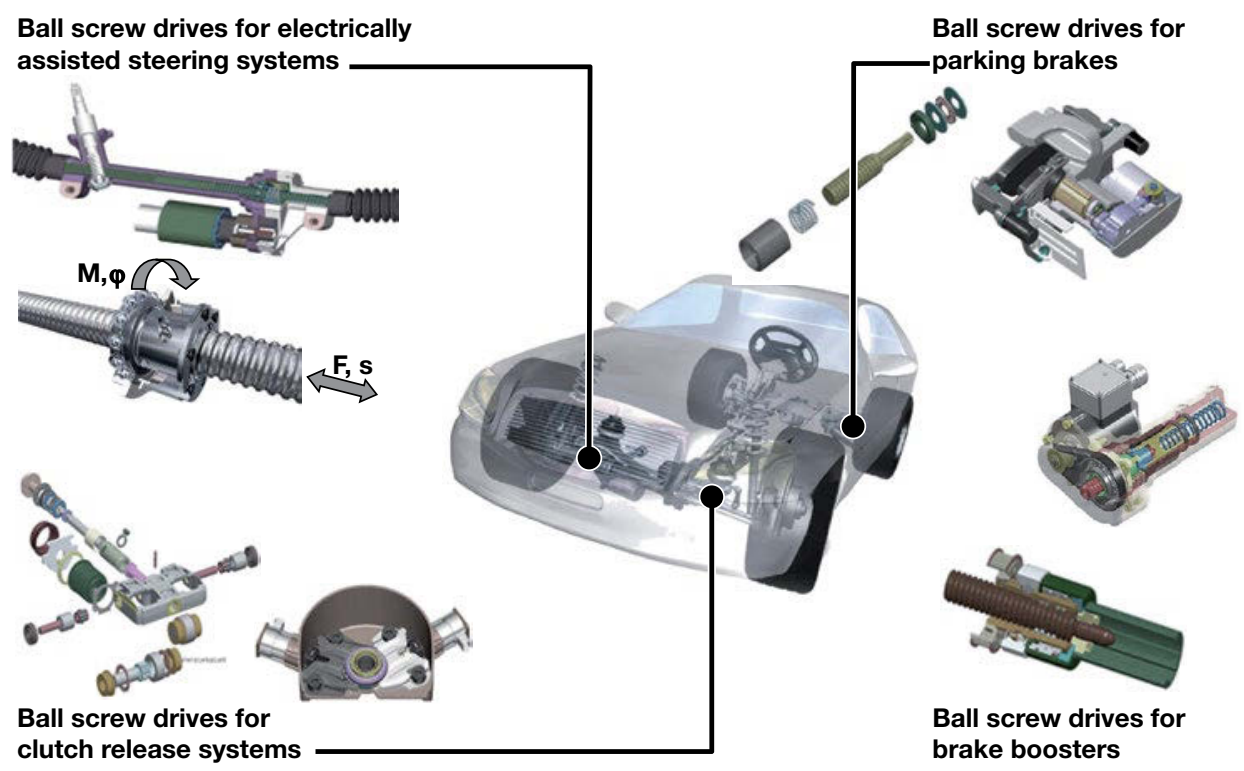

Figure 6 Overview of ball screw drive applications 


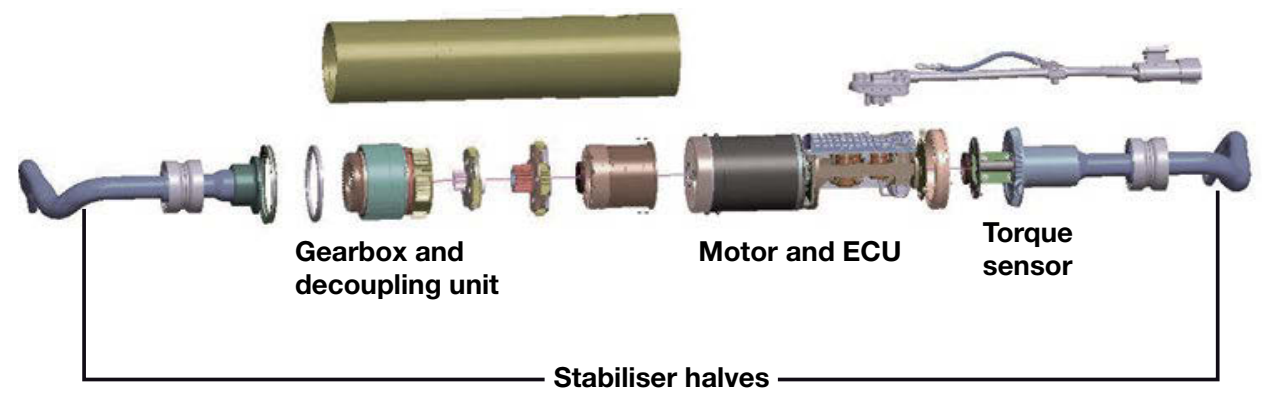

Figure 7 Design of the anti-roll system

This steering ball screw drive is designed along the lines of the principle of modular design and can cover a wide range of applications. It provides a virtually constantly high degree of efficiency of more than $90 \%$ over the entire temperature range and is supplied together with a four-point support bearing. Ball screw drives and support bearings designed to meet customer requirements of minimized backlash can be provided.

In parallel to this, a compact ball screw drive with a pitch diameter of up to $4 \mathrm{~mm}$ has been developed; this compact version has been used by Continental in its electric parking brake since 2011. Other applications based on this design are currently in the development phase - for instance, application in the electromechanically operat- ed brake booster. Figure 6 shows other potential applications for the compact ball screw drive.

\section{Electromechanical anti-roll system}

Over the last few years, Schaeffler has played its role in driving the replacement of hydraulic with electromechanical systems thanks to developing an electromechanical anti-roll system. The plan is for series production of this system to start in 2015. The benefits offered by the system are:

- Little or no tilting of the vehicle when cornering as a function of the present lateral acceleration

- More accurate steering behaviour, improved agility and stability

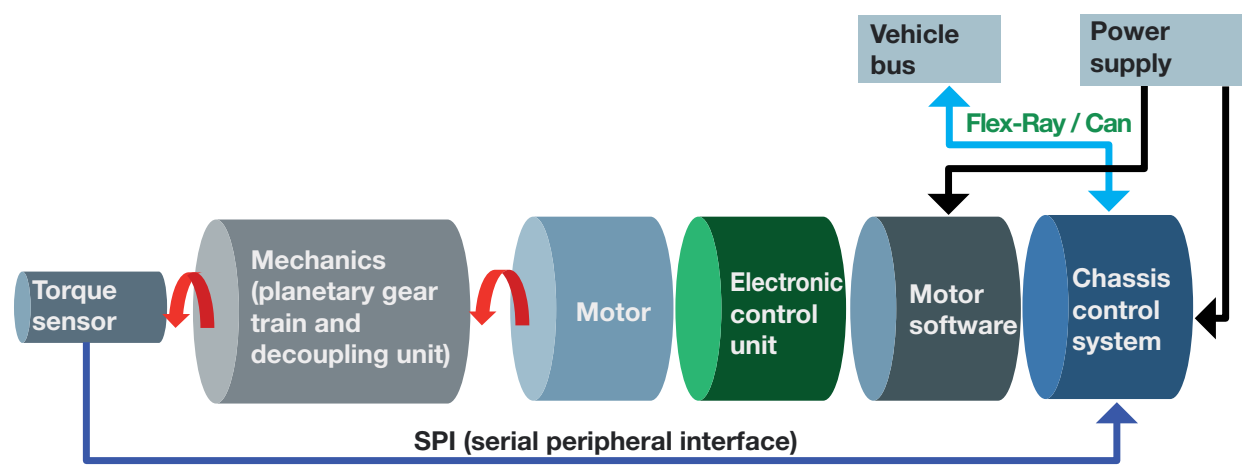

Figure 8 Actuator system architecture 
- Enhanced system dynamics compared to hydraulic systems

- Simple installation and easy maintenance

- Reduction in the number of field complaints by up to $30 \%$ compared to hydraulic systems

- Installation in hybrid vehicles possible

- Reduction in fuel consumption of up to 0.3 litres compared to hydraulic anti-roll systems, and

- Weight neutral compared to hydraulic systems

The system comprises a brushless direct current motor with control system, transmission, torsion bars and a decoupling unit (Figure 7). The E/E architecture is shown in Figure 8.

To complement a pure rotary actuator and to enhance comfort, the Schaeffler solution features a decoupling element, which enables one-sided disruptions in the road surface to be absorbed. Transmitting pulses to the body is thereby also reduced as well as strong vertical motion caused by one-sided disturbance excitation. Design and function of the antiroll system are explained in detail in [4] and [5]. The effect of the decoupling unit for small disturbance excitations is shown in Figure 9.

The decoupling unit demonstrates excellent efficiency particularly for small disturbance excitations with an amplitude of up to $5 \mathrm{~mm}$. Larger disturbance excitations can be corrected by the disturbance con-

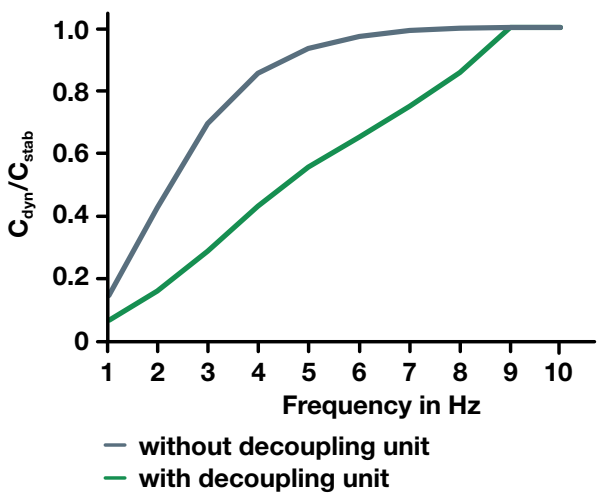

Figure 9 Dynamic stiffness as a function of the frequency of one-sided disturbance excitation for systems with and without a decoupling unit

troller. As the input parameter, this controller requires different functions, including the torque in the anti-roll system and the vertical displacement of the wheels. The overall controller structure is shown in Figure 10.

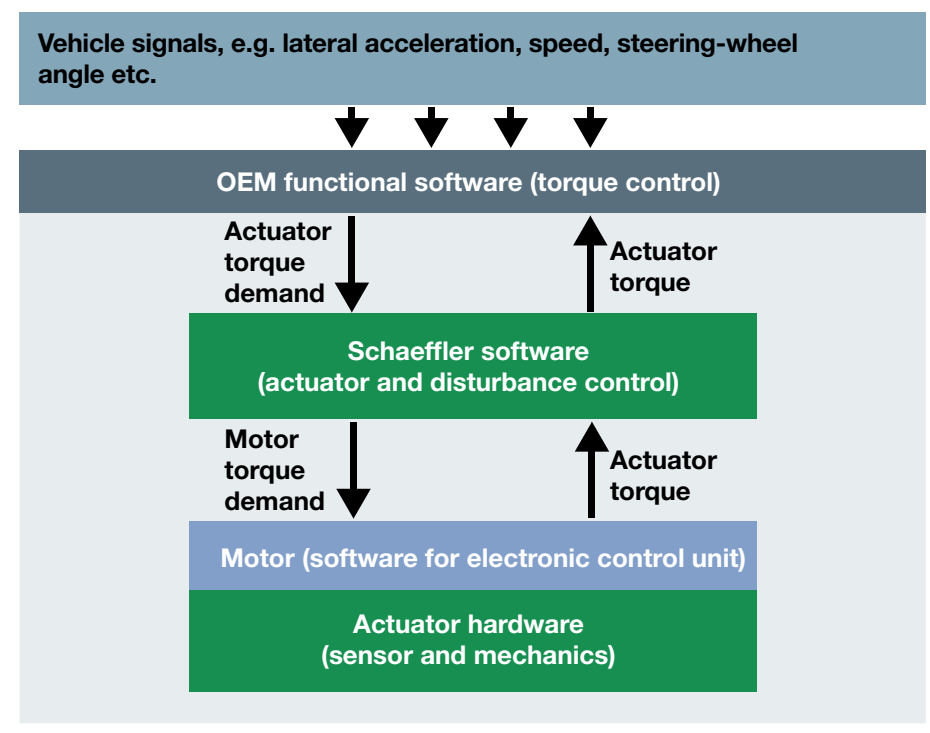

Figure 10 Block diagram of the anti-roll system 
The interference

can be corrected up to a frequency of approximately $8 \mathrm{~Hz}$. The maximum frequency depends on the amplitude. If the information about the road surface collected by a stereo camera is available as the input signal and information from the navigation system about
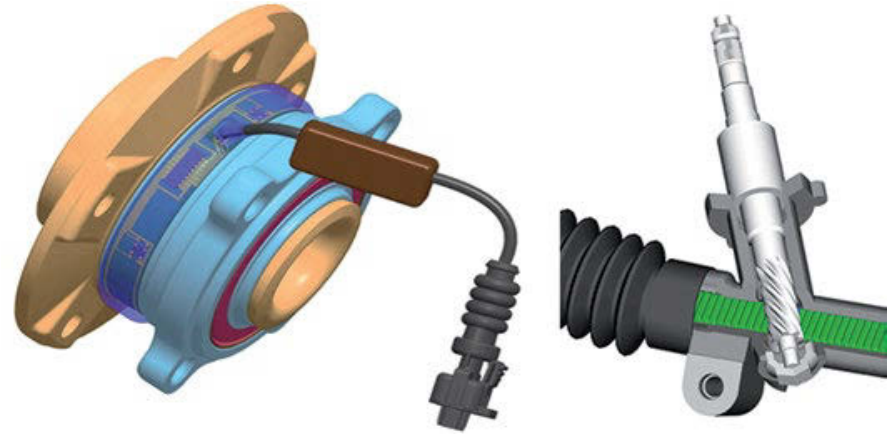

Figure 11 Sensor layer for measuring the wheel force at the wheel bearing (on the left) and for measuring the steering moment in the steering gear used, the distur-

bance controller can be improved still further by means of anticipation.

Alternatively, the body tilt and the effect of one-sided disturbance excitation on the body can also be prevented by hydraulically adjustable struts on each wheel. In addition to the anti-roll motion, this kind of system also prevents a pitching motion during braking and accelerating. However, this does not apply to air-sprung systems on account of the compressibility of air.

\section{Future Schaeffler solutions}

\section{Sensor layer for measuring wheel force}

Schaeffler is currently developing a sensor layer for measuring wheel force; this layer can be applied to two or three-dimensional components such as bearing components. Figure 11 shows several examples of applications. Application to the wheel bearing enables the wheel force to be measured and thus record the forces acting on the wheel, including the brake forces generated during braking. These forces can be used as an input signal for various chassis control systems. The wheel force measurement being developed at Schaeffler also enables accurate recording of the vehicle weight, which may be of interest for light commercial vehicles.

The measurement principle is based on the arrangement of strain gauges on a twodimensional or three-dimensional tensioned surface. The strain gauges are attached using thin-film technology. The basic layer design is shown in Figure 12.

The geometry of the strain gauges is "cut" into the sensor layer using laser, with a top cover attached to protect the sensor layer. To illustrate the technology, Figure 13

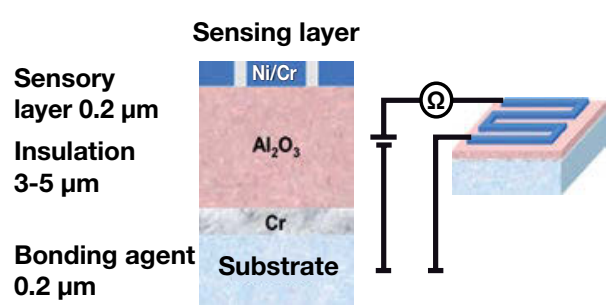

Figure 12 Sensor layer design 

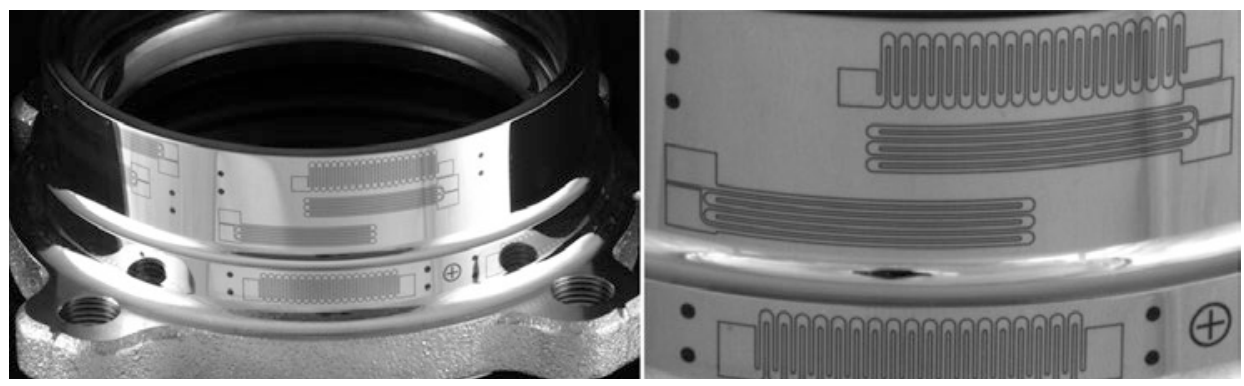

Figure 13 Sensor layer on a bearing outer ring

shows an applied sensor layer using a bearing outer ring as an example.

As proof of the measurement accuracy, it is helpful to compare this layer with a laser extensometer. Experiments with planar samples, which were stretched on a traction engine and their elongation in synchronously recorded with the sensor layer as well as using the laser extensometer, have provided fairly good correlation (Figure 14).

The past few years have seen that the process reliability of the individual process steps has been systematically demonstrated and increased. Currently, preparations for winning projects and customers are being ramped.

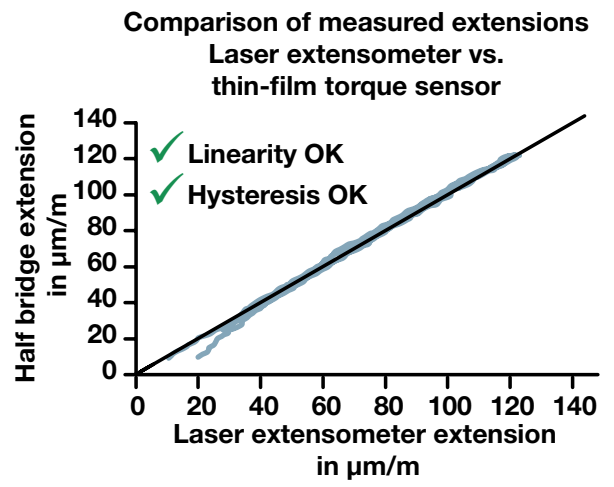

Figure 14 Comparing the elongations of planar samples with the sensor layer

\section{Level adjustment}

In today's vehicles, air suspension is used to adjust the ride height to various driving and load conditions. This suspension system can inherently absorb very poor lateral forces and is therefore not well-suited to McPherson strut axles. In addition, the costs for air springs are another reason the system has not become established in the $B$ and $C$ segments. Hydraulic height adjustment systems are used in the sports car sector, in particular on the front axle to make it easier to drive over ramps [6]. The tendency of markets towards potentially failure sensitive hydraulic actuators is to oppose further proliferation of this technology. There is therefore a need for electromechanical systems designed to adapt the ride height.

The following functions can be supported by this kind of system.

- Lowering the vehicle to reduce aerodynamic drag either on all four wheels or only on the front axle to bring a laden car back into the trim position

- Raising the vehicle to make it easier to get in

- Raising a sports car to protect the spoiler when driving over car park ramps

- Raising vehicles for light off-roading, as well as 


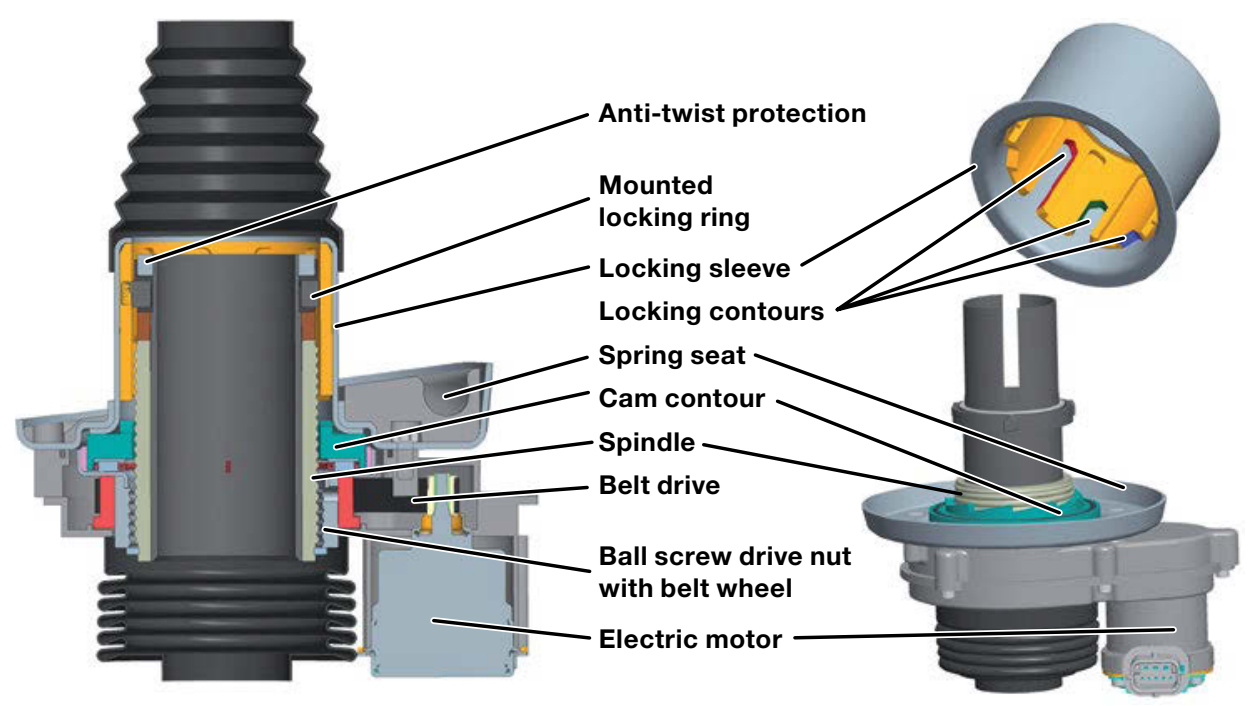

Figure 15 Actuator for the level adjustment on the front axle

- Lowering the vehicle to make it easier to load the luggage compartment

The solution developed by Schaeffler is shown in Figure 15.

The actuator essentially comprises a ball screw drive, a belt drive, an electric motor and a locking assembly. In this case, the vehicle load is not supported on the ball screw drive but on the locking assem- bly, which locks the vehicle's ride height. The ball screw drive itself is only used to adjust the different heights. Figure 16 shows a detailed view of the locking assembly.

The spindle is fixed on the damper to raise and lower the vehicle, while the nut is driven by a belt. The nut rotating leads to an axial displacement

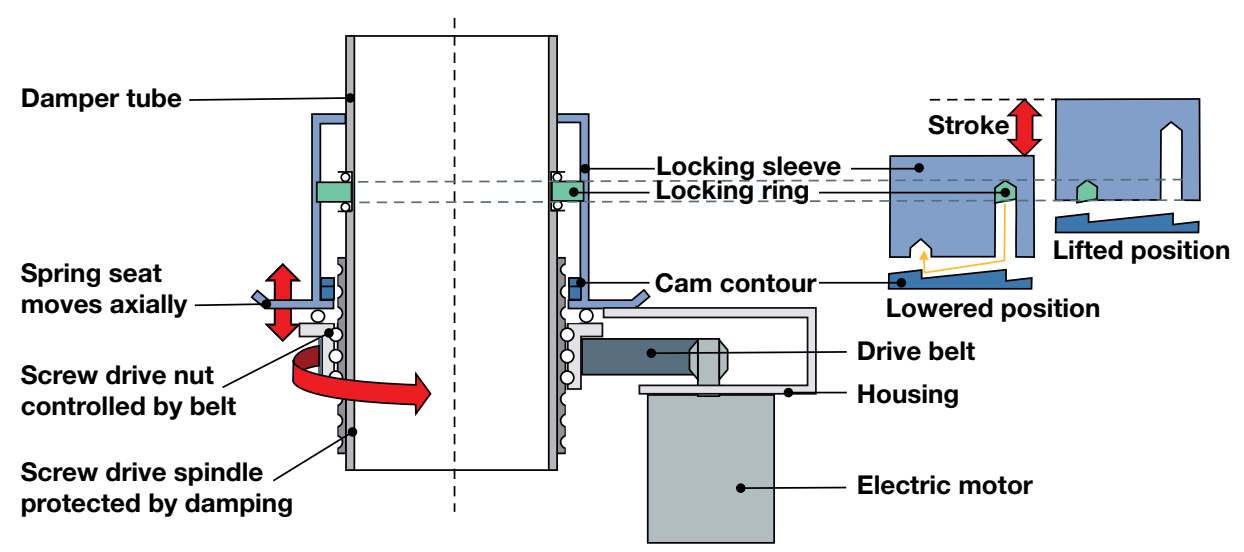

Figure 16 Locking assembly in detail 
of the unit comprising the nut, control contour, motor, housing and spring seat, and this is what changes the ride height.

To lock the height, the locking ring engages in different locking contour grooves depending on the position when lowering. This action maintains the vehicle at the required level. As the vehicle is offset in any position on the locking ring, the drive and spindle lock remain load-free in the locked state (Figure 17).

To aid a better understanding, the three different ride heights and resulting design

\section{Power flow when lifted and lowered}

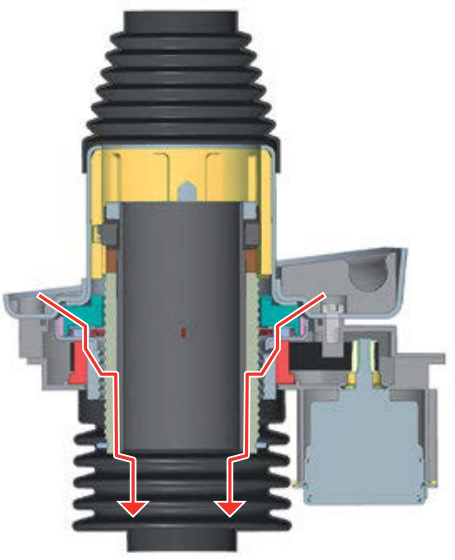

Power flow when locked

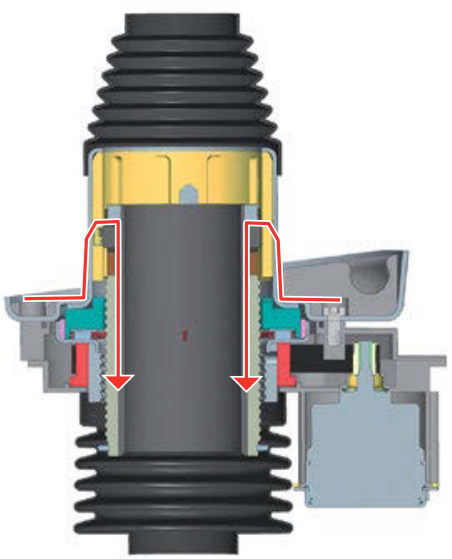

Figure 17 Power flow during raising, lowering and locking

positions of the actuator are summarised in Figure 18. The number of grooves determines the possible ride height. A third groove means that a central position can also be realised.

Bottom position

Central position

Top position
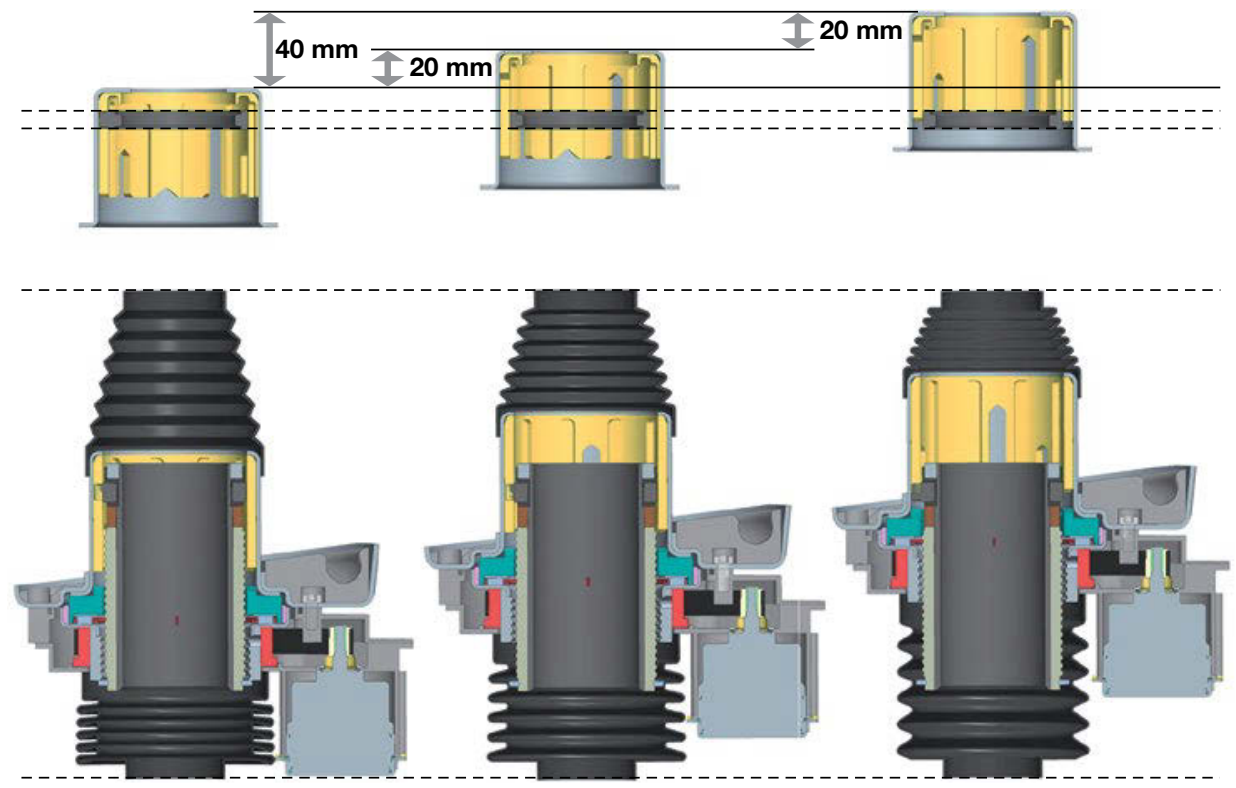

Figure 18 Position of the actuator at different ride heights 
The current engineering knowledge enables adjustment ranges of $40 \mathrm{~mm}$, which can be extended even further depending on the available space. The selected design also allows installation on the rear axle, where dampers and springs are often arranged separately. The only action needed to accommodate this installation is to merely rotate the motor by $180^{\circ}$ (Figure 19).

For E/E implementation, E/E components are already available on the market. Selected ECU includes two power stages, they can

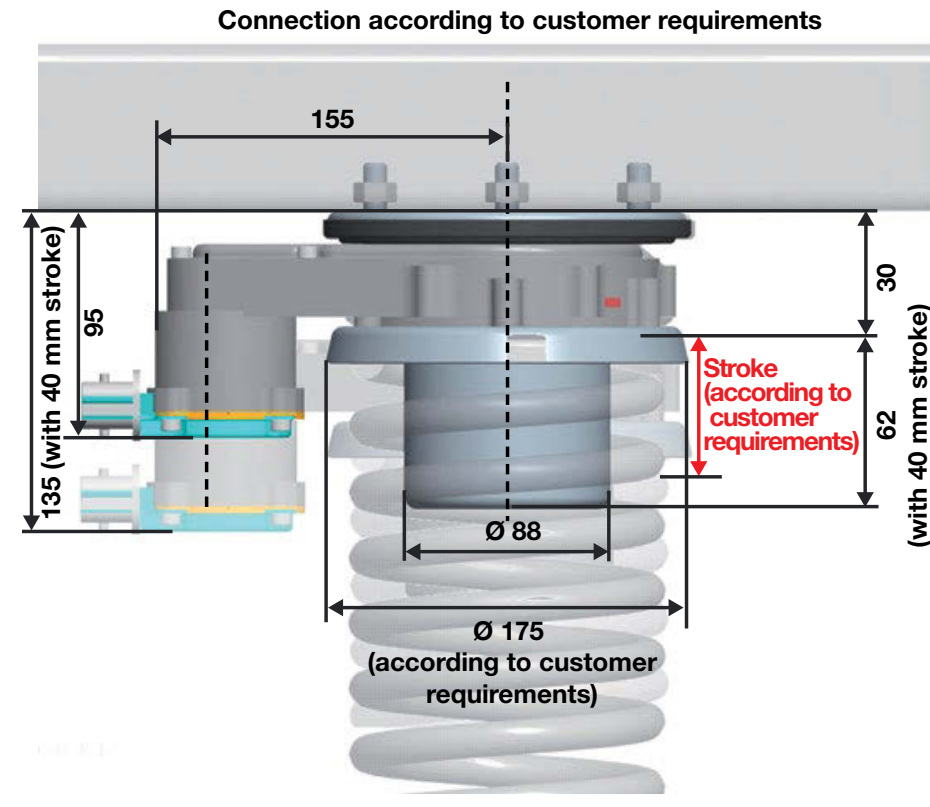

Figure 19 Installation position of the actuator on the rear axle control two electric motors simultaneously. The resulting system architecture is shown in Figure 20.

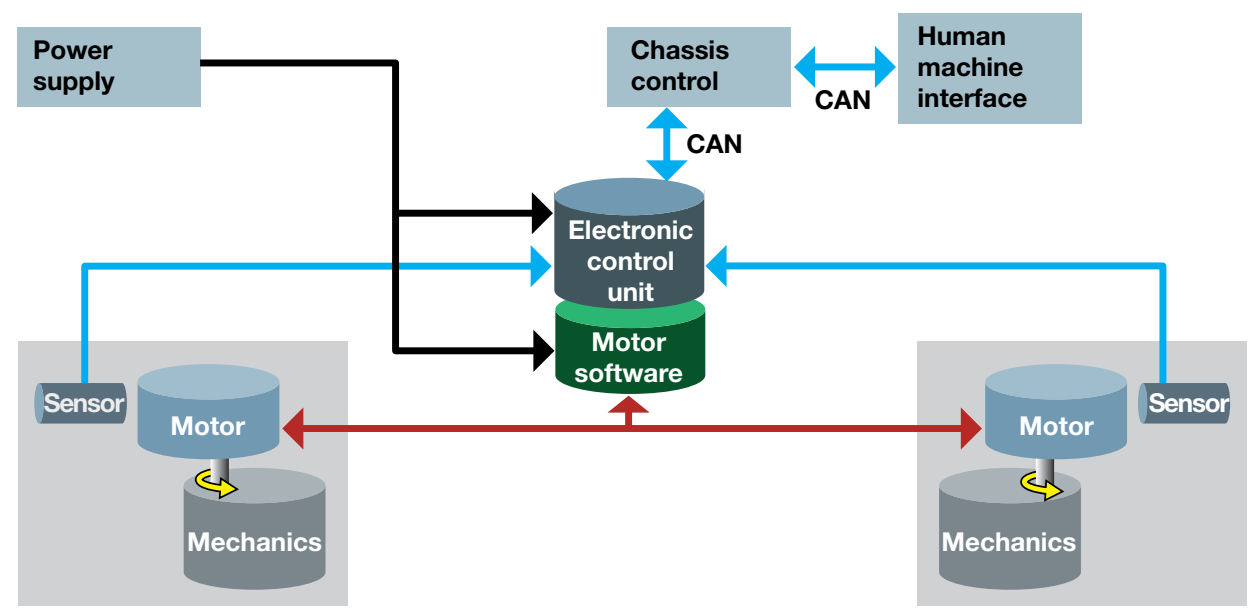

Figure 20 System architecture of the level adjustment 
The proposed system configuration can be seen in Figure 21.

By virtue of the actuator design, selected system architecture and proposed system configuration, the market is filled with diverse and promising applications. Preparations are currently underway to construct test vehicles this year.

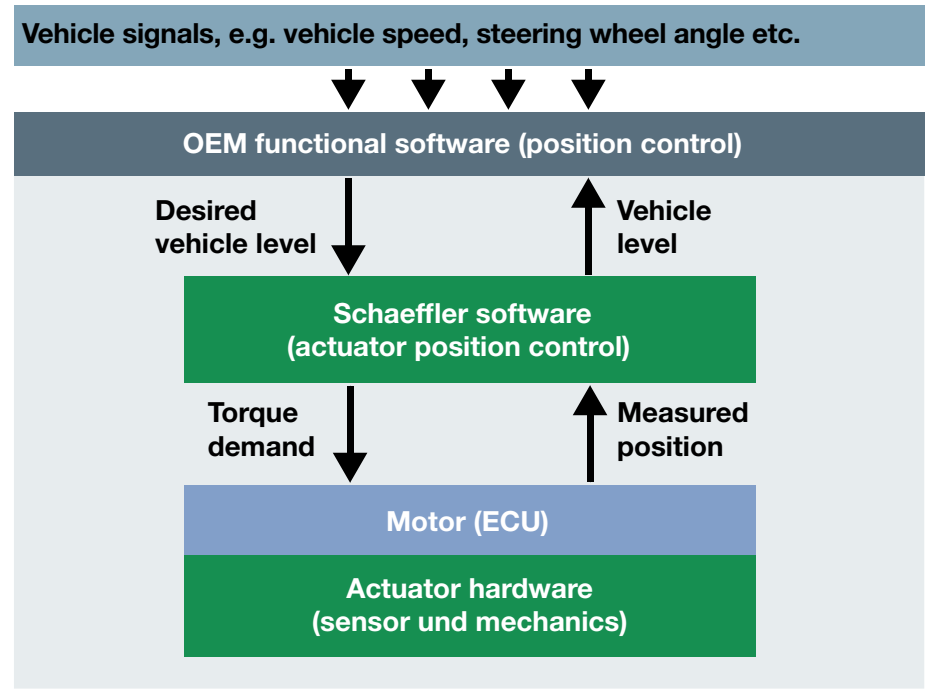

Figure 21 System configuration for the level adjustment

\section{Actuator camber and toe-in actuation}

The approach taken by Schaeffler for camber and toe-in actuation is based on an eccentric drive, which is mounted to the rear axle carrier, that can be designed as an individual wheel actuator [7]. Figure 22 shows the mechanical concept.

The axle-side actuator provides actuation of the toe-in and/or support arm. The

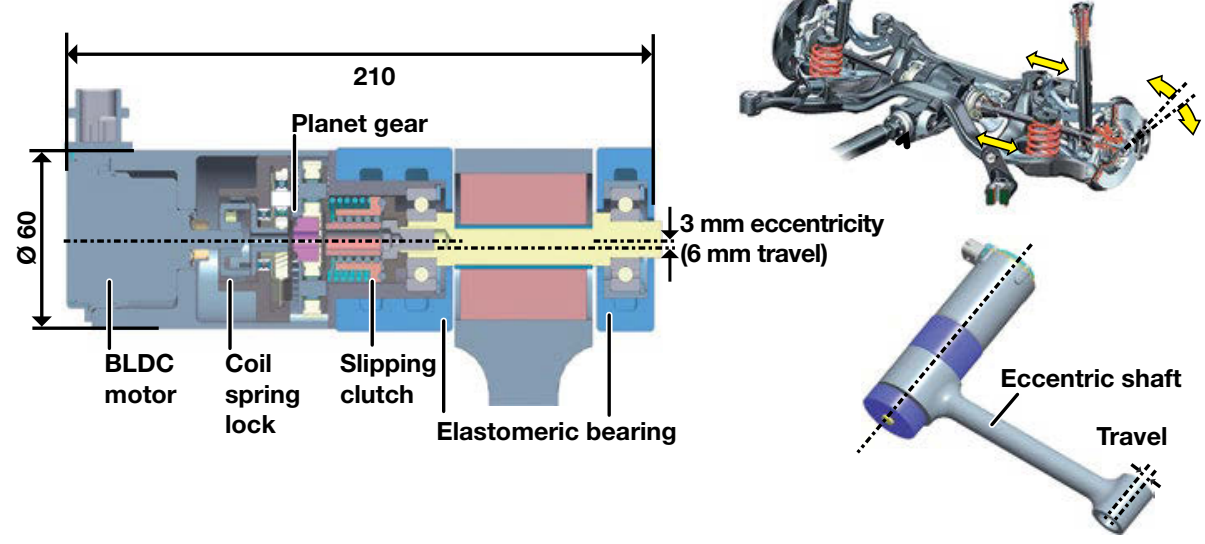

Figure 22 Design of the eccentric actuator for use on the rear axle carrier 
actuation speed and force are based on the power of the selected drive. The actuation travel is a function of the underlying eccentric feature. The E/E architecture uses the $E / E$ components familiar from the level adjustment system with two integrated power stages to control two electric motors. This results in the following actuator characteristics:

- Actuation travel $=6 \mathrm{~mm}$ in the case of this eccentricity of $3 \mathrm{~mm}$,

- Maximum actuation time $<2 \mathrm{~s}$

- Maximum actuation load $5 \mathrm{kN}$

- Actuator diameter < $65 \mathrm{~mm}$

To reduce the engine speed, a worm wheel or planetary gear train can be used. Another feature of the drive is its overload clutch, as well as mechanical short circuit to protect the bearings. Furthermore, the actuator can be integrated into an elastomer metal cartridge on request.

Previous customer feedback indicates that the market is looking for an alternative to the linear actuator on the rear axle. This alternative does not always need highly dynamic actuation. The stated actuation time of 2 seconds for toe-in actuation with a noticeable reduction in turning circle is usually sufficient. Current plans are to kit out a prototype vehicle this year.

\section{Developing the anti-roll system}

In the course of developing the anti-roll system further, a split stabiliser is opened for driving in a straight line and closed when cornering. Thus, a quasi-static tension state is produced when cornering. When driving in a straight line, however, the stabiliser is open and rolling movements of the bodywork for the reciprocal disturbance excitation through the road to the opposite side of the vehicle, are suppressed.
In order to significantly reduce the vehicle's rolling angle when cornering, the stabiliser rigidity is increased by more than $20 \%$ compared to a passive stabiliser. The design for this type of anti-roll system is shown in Figure 23.

In this design, the clutch is actuated via electromechanical linear actuator (consisting of electric motor, ball screw), such as depending on the steering angle and vehicle speed and other vehicle status parameters. The functional principle of the clutch is based on a locking device developed at Schaeffler, the design of which is also shown in Figure 23.

The current engineering knowledge has a weight of $3.5 \mathrm{~kg}$ without stabiliser halves. Compared to the design used in series pro-
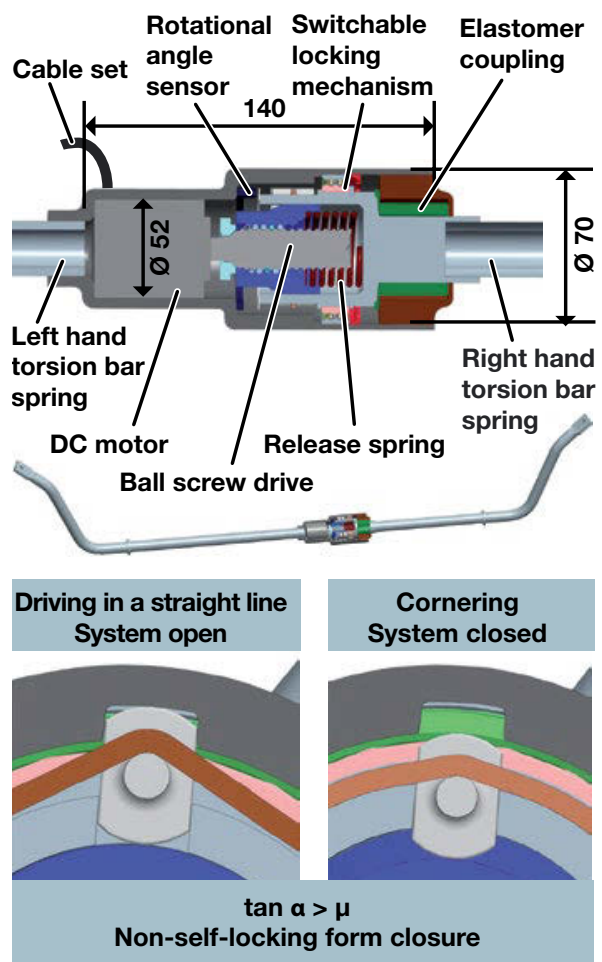

Figure 23 Split anti-roll stabiliser 
duction, this equates to a weight reduction of more than $50 \%$. If the stabiliser halves are not designed as steel pipes, but in glass fibre reinforced plastic, this produces a potential total weight of the entire actuator of around 4 to $4.5 \mathrm{~kg}$.

\section{"Switchable" wheel bearings}

Schaeffler has developed a triple row wheel bearing to reduce friction compared to the tapered roller bearings used in general and for higher wheel loads. This bearing features two equally tensioned rows of balls. To further reduce friction, the bearing can be designed such that only the outer rows of balls are used when driving in a straight line, and the central row is engaged when cornering. This is done by specifically changing the bearing preload, as shown in Figure 24.

The balls with their spring deflection are shown as springs.

Only the outer rows of balls are loaded when driving in a straight line; the central row is not loaded. When cornering, the central row (which is designed a four-point contact bearing) is engaged in order to support the drive performance in the bend by providing the required high level of rigidity. To this end, only a few oversized balls are fitted in the four-point contact bearing, which means that the remaining balls in the cage have clearance and reduce friction when driving in a straight line. When cornering, these balls are in contact and then absorb the required forces. Initial simulation results show an additional reduction in friction of more than $25 \%$.

\section{Active electromechanical damping}

One possible approach of realising an active, or at least partially active, chassis is produced by using an electromechanical
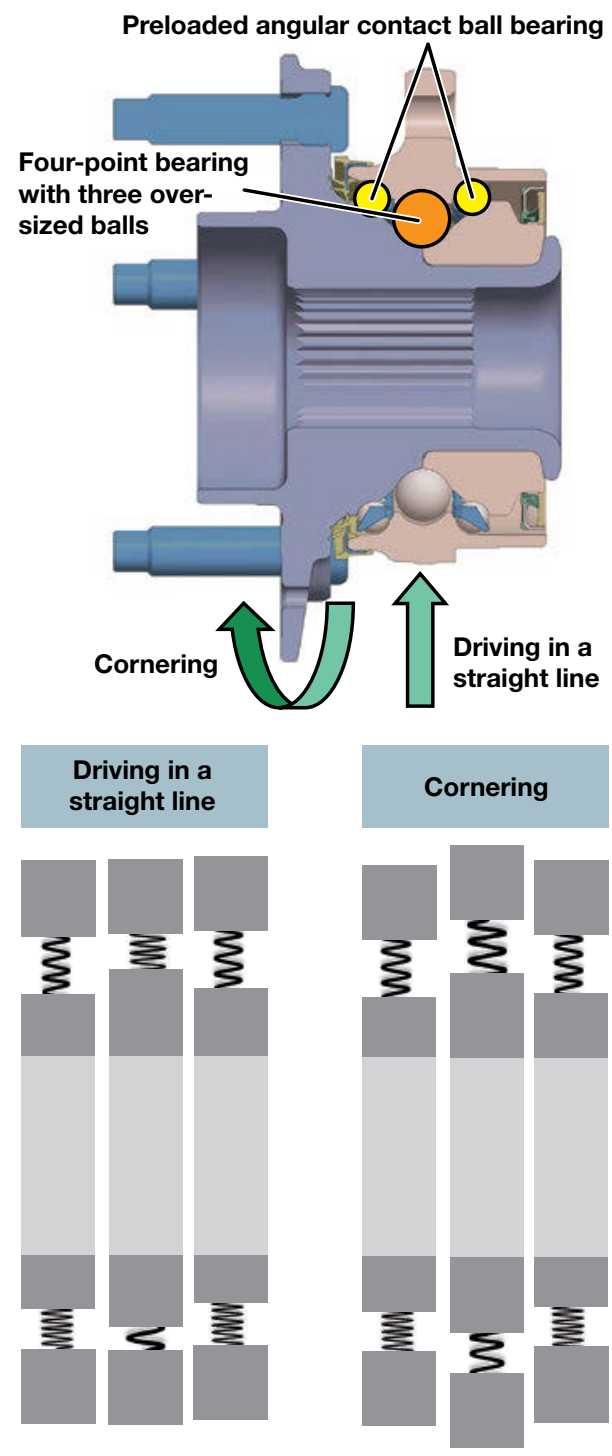

Figure 24 Switchable wheel bearing with offset outer rows of balls

damper; this damper simultaneously works as an actuating element and actively feeds forces into the chassis. The idea of being able to utilise the lost energy of vehicle damping has been explored for over 


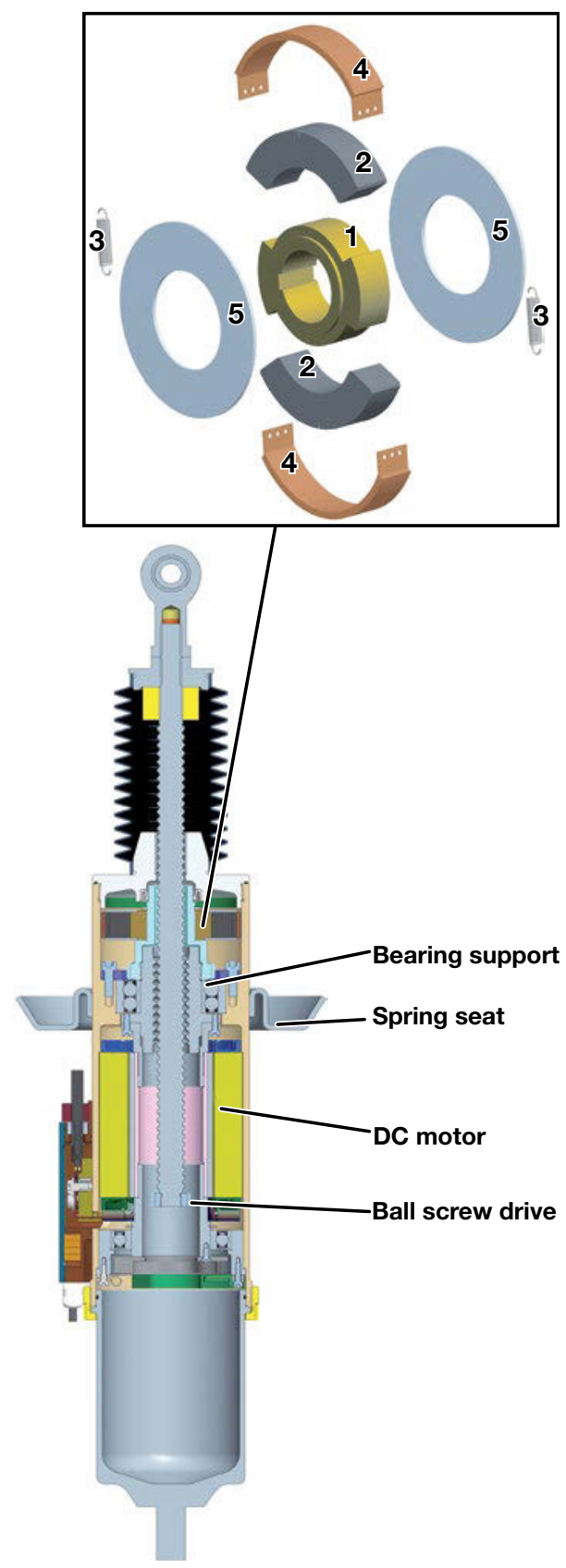

Figure 25 Design of active electromechanical damping
20 years; the result is to use a brushless direct current motor using a ball screw drive to transfer the vertical motion of the wheel in a rotational motion of the rotor, thereby recuperating the damping energy [8].

What's more, this kind of damper provides the prerequisite for optimising the damping characteristic curves beyond the options offered by the hydraulic system [9]. At the same time, it forms the basis for realising a (partial) active suspension. Previous solutions show an unfavourable cost-benefit ratio and are also difficult to integrate into the space available. In addition, other requirements, such as overload capability or the response characteristic for small excitations, have prevented further development in this field.

Schaeffler is continuing to develop an actuator, which will fit as far as possible in the existing space of a hydraulic damper, that offers a better cost-benefit ratio than previous solutions as well as improved overload capacity. The basic configuration of the damper comprises a brushless direct current motor, a ball screw drive with bearing arrangement and a damper pipe (Figure 25).

The wheel module with McPherson strut is excited vertically through the road surface. This translation is converted in the damper to a rotation and dampened by the regenera-

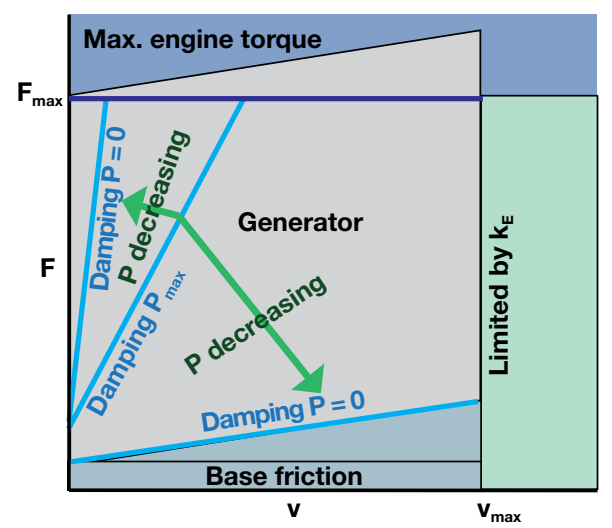

Figure 26 Characteristic curve and application area of an electric damper 
tively operated electric motor. A centrifugal brake is used to slow down the rotor rotation in the electric motor in the event of large pulses. The design of the electric damper is based on the characteristic curve of the damper during a suspension and rebound of a hydraulic damper as well as being based on the physical limits of the electric motor in generator mode (Figure 26).

To obtain basic findings, Schaeffler designed an electric damper (identical to the one seen in Figure 25) and tested it on the test rig. The findings for four different road surfaces $(A, B, C, D)$ are shown in Figure 27; the amplitude and speed increase in alphabetical order. Significant regenerative power is achieved with excitation profile $C$ and $D$, but is more likely to be achieved on poor roads or when off-roading. If one assumes "normal" amplitudes of 10 to $30 \mathrm{~mm}$ in ac-

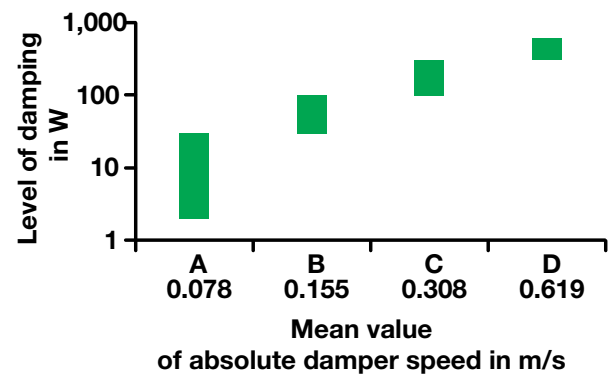

Figure 27 Measured power generated a function of damping force and speed

cordance with profile $A$ and $B$, the resulting regenerative power ranges from 20 to $30 \mathrm{~W}$. This is too little power to justify high volume production purely on the grounds of energy regeneration. Another option is if the damper can also be used in the chassis as an

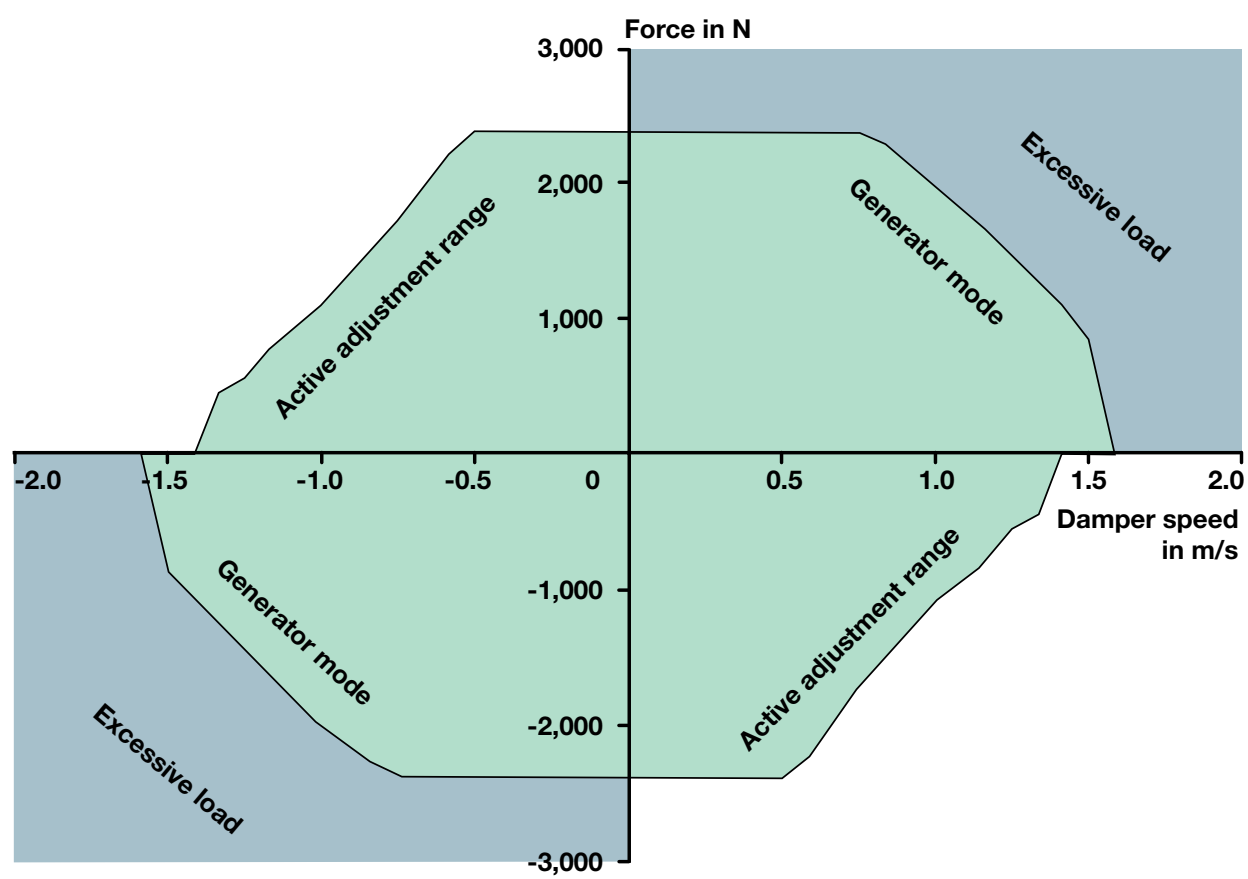

Figure 28 Characteristic diagram of the active electromechanical damping with generator mode and active adjustment range 
actuating element [11[. The derivation of the underlying function equations of the damper is performed using the quarter vehicle model [10].

The installed electrical output of around $1.9 \mathrm{~kW}$ per wheel enables active engagement in the chassis. The characteristic diagram of the electromechanical damper is shown in Figure 28. The overload capability is a result of the centrifugal brake function.

With the active electromechanical damping, the entire range [12] of a possible influence on the driving dynamics can be extended, thereby significantly boosting the benefit for customers. The series production use of technology now depends on customer acceptance, which is to be studied over the coming months.

\section{Outlook}

The range of the chassis applications offered by Schaeffler requires a multi-pronged approach when developing new products. Firstly, customers in an extremely cost-driven and competitive market should be provided with added value when it comes to bearing applications; this can be achieved by offering innovative developments. Secondly, mechanically oriented innovations form a sound basis for designing new mechatronic chassis systems. In addition, the task for Schaeffler engineers is also to create and realise added with new and trend-setting concepts. The objective of all these efforts is to generate function added value particularly in terms of power density, energy efficiency, weight and functional integration as well as to create cost benefits compared to today's technology. To do this, the broad knowledge and experience held within the Schaeffler Group as well as that experience of selected cooperation partnerships will be used in a specific manner.

\section{Literature}

[1] Ammon, D.: Herausforderung Fahrwerkstechnik, Tagungsband Chassistech 2009, pp. 1-24

[2] Krüger, M., Kraftfahrzeugelektronik, 2008, 2. Auflage, S. $21 \mathrm{ff}$

[3] von Hugo, C., The next step towards autonomous driving. 22 ${ }^{\text {nd }}$ Aachen Symposium, 2013, pp. 751-765

[4] Krimmel, H.; Deiss, H.; Runge, W.; Schürr, H.: Elektronische Vernetzung von Antriebsstrang und Fahrwerk. ATZ 108, 2006, no. 5, pp. 368-375

[5] Beiker, S.; Mitschke, M.: Verbesserungsmöglichkeiten des Fahrverhaltens von Pkw durch zusammenwirkende Regelsysteme. ATZ 103, 2001, no. 1, pp. 38-43

[6] Hohenstein, J.; Schulz, A.; Gaisbacher, D.: Das elektropneumatische Vorderachsliftsystem des Porsche 997 GT3. ATZ 112, 2010, no. 9, pp. 622-626

[7] Kraus, M.: Actuators for Challenging Chassis. $8^{\text {th }}$ LuK Symposium, 2006

[8] US patent 5091679, 1990

[9] Kraus, M.: Chassis Systems - Schaeffler Can Do More Than Bearings. $9^{\text {th }}$ Schaeffler Symposium, 2010

[10] http://web.mit.edu/newsoffice/2009/shockabsorbers-0209.html

[11] Willems, M.: Chances and Concepts for Recuperating Damper Systems. 21 $1^{\text {st }}$ Aachen Symposium, 2012

[12] Rau, M.: Koordination aktiver Fahrwerk-Regelsysteme zur Beeeinflussung der Querdnynamik. Dissertation University of Stuttgart, 2007, pp. 91-122

Open Access. This chapter is distributed under the terms of the Creative Commons Attribution Noncommercial License, which permits any noncommercial use, distribution, and reproduction in any medium, provided the original author(s) and source are credited. 